\title{
Introduction to thermoacoustic Stirling engines: First steps and praxis
}

\author{
Carmen Iniesta ${ }^{* 1}$, José Luis Olazagoitia ${ }^{1}$, Jaime Gros $^{1,}$, Jordi Vinolas $^{1}$, Javier Aranceta ${ }^{2}$ \\ ${ }^{1}$ Nebrija University, Campus de la Dehesa de la Villa, Calle Pirineos, 55, 28040 Madrid, Spain \\ ${ }^{2}$ CS Centro Stirling, S. Coop., Avda. Alava, 3 E-20550 Aretxabaleta-Guipúzcoa, Spain
}

\begin{abstract}
The work focuses on the theoretical study and design of Thermoacoustic Stirling-Like Cycle Engines. One of the main goals of this study is to describe the application of a methodology for energy analysis and optimization of thermoacoustic devices. This new approach avoids complicated mathematical treatments, facilitates access to this fascinating technology for all audiences. The presented methodology is based on the distribution of the active and reactive acoustic power flow according to the passive acoustic circuit. In addition, this methodology allows optimizing the device by comparing different acoustic circuits. This method is evaluated at a theoretical level with the models and simulations developed, for each of the case studies described. Besides, this publication shows the praxis from the first steps, so the reader is guided in the design and manufacture of a compact Stirling thermoacoustic energy recovery engine, operating in laboratory conditions. The resulting demonstrator is itself an academic tool for knowledge transfer.
\end{abstract}

\section{Introduction}

The energy transition implemented at a global level implies restrictions and regulations that greatly affect the transport sector. The International Energy Agency estimates that $23 \%$ of greenhouse gas emissions come from this sector. The regulation (EU) 2019/631 aims to reduce greenhouse gas (GHG) emissions in the EU by setting limits for new passenger cars to make road transport cleaner and to contribute to the goals of the Paris Agreement [1]. The vehicles used today, whether combustion or hybrid, are machines that have great inherent inefficiencies during their operation. It is estimated that in vehicles with internal combustion engines, approximately $20 \%$ of the chemical energy stored in the fuel tank is converted into useful work that is invested in the operation of the vehicle itself. The remaining energy is lost in several of their systems by mechanical dissipation and most of it, a third, by heat dissipation through the exhaust system.

In an attempt to recover "wasted" thermal energy, different technologies have been developed in the field of "Waste Heat Recovery" and "Energy harvesting": Organic Rankine Cycle (ORC) ${ }^{1}$; Turbo-Compound Technology (Mechanic ${ }^{2}$ and electric ${ }^{3}$ Turbo-

\footnotetext{
* Corresponding author: miniesta@,nebrija.es
} 
Compound, TC and eTC); thermoelectric generators (TEG) ${ }^{4}$ and Stirling type thermoacoustic engines (Thermoacoustic Stirling Like Cycle Engine, TA-SLiCE) ${ }^{5}$.

Table 1 shows the virtual results for a complete car model corresponding to a study presented by Tenneco at the Vehicle Thermal Management Systems (VTMS) Congress ${ }^{6}$. The study evaluates and compares the amount of waste heat recovered by each technology and the type of energy generated, as well as its impact on fuel savings. Interestingly, it was found that there is no correlation between the amount of waste heat recovered and fuel savings.

Table 1. Comparative performance indicators for vehicle waste heat recovery technologies.

\begin{tabular}{|c|c|c|c|c|}
\hline Technology & $\begin{array}{c}\text { Energy collected } \\
\text { in the exhaust [\%] }\end{array}$ & $\begin{array}{c}\text { Fuel } \\
\text { savings [\%] }\end{array}$ & $\begin{array}{c}\text { Fuel savings vs. Energy } \\
\text { harvested ratio [\%] }\end{array}$ & Weight [kg] \\
\hline ORC & 7 & 4 & 57 & $15^{7}-25$ \\
\hline TC \& eTC & 19 & 1 & 5 & $75-325^{8}$ \\
\hline TEG & 2.5 & 0.7 & 28 & $200^{9}$ \\
\hline TA-SLiCE & 3.5 & 2.7 & 77 & $35^{10}$ \\
\hline
\end{tabular}

Fuel savings vs. Energy harvested ratio data in Table 1, identifies TA-SLiCE to be the most promising technology in terms of efficiency and, at the same time, it is one of the technologies with the most options for innovation, given that it has not yet reached a high degree of maturity. This fact, leave room for improvement in TA-SLiCE's most significant limitation: it's low power density. Among the advantages of TA-SLiCE technology over the other technologies shown in Table 1, the most important are its simple configuration with almost no moving parts, making it particularly reliable, reducing low manufacturing and maintenance costs, and avoiding the use of damaging lubricants. Since they are external combustion engines, they can be powered by renewable thermal sources as well as thermal energy dissipated in other processes as is the case for the exhaust system of a vehicle combustion engine.

The convergence of the Stirling engine study with the development of thermoacoustic energy conversion is quite recent, with a history of only 40 years. Ceperley observed in 1979 that the flow paths of the working fluid molecules followed a sequence similar to that of the Stirling cycle. Since then, Backhaus and Swift presented the first thermoacoustic Stirling-like cycle engine (TA-SLiCE), based on travelling-wave phasing ${ }^{11}$. It became the latest evolution in conventional Stirling engines, dramatically simplifying their mechanics since the TA-SLiCE lacks pistons. Figure 1 shows the main components of a TA-SLiCE concept design.

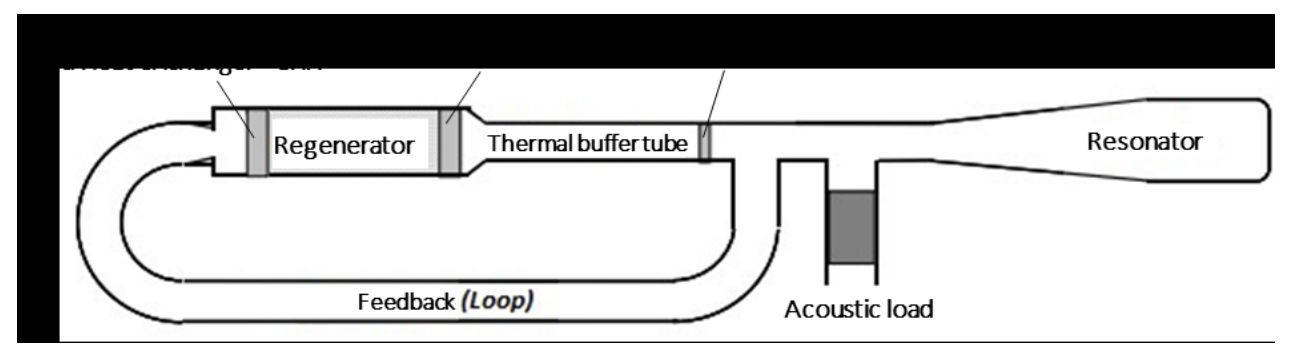

Fig. 1. Diagram of the main components of a TA-SLiCE.

For the TA-SLiCE generator to work, a resonant passive acoustic circuit, consisting of a feedback loop (Compliance and inertance) and a resonating acoustic power extraction 
branch, is required to originate and maintain oscillations in a compressible fluid (gas) ${ }^{12}$. The acoustic circuit houses a set of key components for the thermoacoustic effect to take place, named the active core of the TA-SLiCE (a heater (HHX), a cold heat exchanger $\mathrm{CHX}$ and a regenerator (REG) interposed between them, in addition to the thermal buffer tube, TBT). On the other hand, the generated acoustic energy can be quantified using an acoustic load and also extracted, using different types of electroacoustic transducers ${ }^{13}$.

In contrast to the traditional Stirling engines the gas parcels into the regenerator experience the Stirling cycle at a microscopic scale inside the regenerator of a TA-SLiCE upon which a thermal gradient has been established. The work undergone by each of the gas parcels when completing a whole Stirling cycle inside the regenerator results in amplification of the wave. In this way, the acoustic power at the output of the regenerator is amplified.

In a TA-SLiCE, the feedback loop design (compliance and inertance segments) is critical to the efficient integration of the travelling wave characteristic motion with the Stirling cycle performance.

The Design Environment for Low-Amplitude Thermoacoustic Energy Conversion software (DeltaEC) is the most widely used software for simulating TA-SLiCE technology. The conventional energy analysis of thermoacoustic devices made by DeltaEC models takes into account only the active power, based on the Rott linear theory published by Swift 14. That approach considers that feedback inertances and compliances do not dissipate or produce acoustic energy, but simply transmit it by modifying the phase of the pressure $\mathrm{p}_{1}$ or the volumetric velocity rate $U_{1}$ of the wave ${ }^{14}$. However, it is not always obvious, simply from the conventional analysis provided by the general theory, to intuitively define how the impedance of the components of the resonant network affects the pressure phasors $\mathrm{p}_{1}$ or volumetric velocity $\mathrm{U}_{1}$ by modifying their phase $\varnothing_{p U}{ }^{15}$.

Against this background, this paper focuses on the theoretical study and design of Thermoacoustic Stirling-Like Cycle Engines (TA-SLiCE) with the application of a methodology for energy analysis and optimization of thermo-acoustic devices, which does not exist so far in the specialized literature. This new perspective, which avoids complicated mathematical treatments, facilitates access to this fascinating technology for all audiences. The presented methodology is based on the distribution of the active and reactive acoustic power flow according to the passive acoustic circuit ${ }^{16}$. In addition, this approach allows optimizing the TA-SLiCE by comparing different acoustic loops. This method is evaluated at a theoretical level with the models and simulations developed and later qualitatively shown, carrying out tests in some manufactured TA-SLiCE demonstrators. This work has been published in a book to be an introduction to thermoacoustic technology from a practical point of view ${ }^{17}$.

Section 2 summarizes a comprehensive state of the art on TA-SLiCE, classifying each of the technologies presented in the literature according to the electrical power provided. Section 3 describes the theoretical basis of the reactive acoustic power flow modelling of the conceptual TA-SLiCE design and discusses the design of the TA-SLiCE demonstrator following the energetic methodology guideline. Section 4 provides in detail the mechanical design of the TA-SLiCE components. In section 4, the reader is guided in the design and manufacture of a compact Stirling thermoacoustic energy recovery engine, from an academic experience. The most relevant conclusions and are made in section 5 .

\section{Study of feasible TA-SLICE application frameworks}

In this section, a comparison of recent research activity in TA-SLiCE technology is presented in a Table 2: 
Table 2. Comparative performance indicators for different TA-SLiCEs for low-range power output.

\begin{tabular}{|c|c|c|c|c|c|c|}
\hline Authors & $\begin{array}{c}\text { Resonator \& } \\
\text { transducer }\end{array}$ & \begin{tabular}{|c|}
$\begin{array}{c}\text { Working } \\
\text { fluid }\end{array}$ \\
\end{tabular} & $\begin{array}{c}\text { Frequency } \\
(\mathrm{Hz})\end{array}$ & \begin{tabular}{|c|} 
Temperature \\
$\left({ }^{\circ} \mathbf{C}\right)$ \\
\end{tabular} & $\begin{array}{l}\text { Power } \\
\text { output }\end{array}$ & Efficiency \\
\hline Yu et al. ${ }^{18}$ & $\begin{array}{l}\text { Annular resonator } \\
\text { with stub \& cheap } \\
\text { loudspeaker }\end{array}$ & 1 bar air & 70 & $\begin{array}{c}\Delta \mathrm{T}=120 \\
\text { (onset } \\
\text { at } \approx 100 \text { ) }\end{array}$ & $11.6 \mathrm{~W}_{\mathrm{e}, \max }$ & $1.65 \%$ \\
\hline Chen $^{19}$ & $\begin{array}{c}\text { Dual-core loop- } \\
\text { branched \& low-cost } \\
\text { loudspeaker }\end{array}$ & 1 bar air & $\mathrm{n} / \mathrm{a}$ & $\begin{array}{l}\text { Onset at } \\
\Delta \mathrm{T}=230\end{array}$ & $15 \mathrm{~W}_{\mathrm{e}}$ & $3.2 \%$ \\
\hline De Blok ${ }^{20}$ & $\begin{array}{c}\text { Co-axial 2-stage } \\
\text { loop-branched\& low- } \\
\text { cost loudspeaker }\end{array}$ & 1 bar air & $\mathrm{n} / \mathrm{a}$ & $\begin{array}{l}\text { Onset at } \\
\Delta \mathrm{T}=140\end{array}$ & $22 \mathrm{~W}_{\mathrm{e}}$ & $2 \%$ \\
\hline $\begin{array}{c}\text { Backhaus et } \\
\text { al. }{ }^{21}\end{array}$ & $\begin{array}{c}\text { Annular \& two- } \\
\text { opposed linear } \\
\text { alternators }\end{array}$ & $\begin{array}{l}55 \text { bar } \\
\text { helium }\end{array}$ & 125 & $\Delta \mathrm{T}=620$ & $\begin{array}{l}39 \mathrm{~W}_{\mathrm{e}} \& \\
58 \mathrm{~W}_{\mathrm{e}, \max }\end{array}$ & $\begin{array}{l}18 \%(\max ) \\
\& 15 \%\end{array}$ \\
\hline Telesz 22 & $\begin{array}{c}\text { Annular \& two- } \\
\text { opposed linear } \\
\text { alternators }\end{array}$ & $\begin{array}{l}30 \text { bar } \\
\text { helium }\end{array}$ & 100 & $\Delta \mathrm{T}=630$ & $70 \mathrm{~W}_{\mathrm{e}}$ & $1.65 \%$ \\
\hline Luo et al. ${ }^{23}$ & $\begin{array}{c}\text { Loop-branched \& } \\
\text { dual opposed linear } \\
\text { alternator }\end{array}$ & $\begin{array}{l}25 \text { bar } \\
\text { helium }\end{array}$ & 64 & $\Delta \mathrm{T}=650$ & $97 \mathrm{We}_{\mathrm{e}}$ & $4 \%$ \\
\hline$\underset{24}{\text { Kloprogge }}$ & $\begin{array}{c}\text { Co-axial \& } \\
\text { bidirectional turbine }\end{array}$ & 4 bar air & 58.3 & $\Delta \mathrm{T} \approx 550$ & $32.5 \mathrm{~W}_{\mathrm{e}}$ & $\mathrm{n} / \mathrm{a}$ \\
\hline Wilcox 25 & $\begin{array}{l}\text { Coaxial \& two- } \\
\text { balanced linear } \\
\text { alternators }\end{array}$ & $\begin{array}{l}30 \text { bar } \\
\text { helium }\end{array}$ & 50 & $\Delta \mathrm{T}=500$ & $100 \mathrm{~W}_{\mathrm{e}}$ & $7 \%$ \\
\hline$\underset{26}{\text { Wang et al. }}$ & $\begin{array}{c}\text { Annular with phase } \\
\text { modulation object \& } \\
\text { two-opposed linear } \\
\text { alternators }\end{array}$ & $\begin{array}{l}30 \text { bar } \\
\text { helium }\end{array}$ & $\mathrm{n} / \mathrm{a}$ & $\Delta \mathrm{T}=787$ & $\begin{array}{l}71.3 \mathrm{We}_{\mathrm{e}} \& \\
73.3 \mathrm{~W}_{\mathrm{e}, \max }\end{array}$ & $14 \%$ \\
\hline Wu et al. ${ }^{27}$ & $\begin{array}{l}\text { Loop-branched \& a } \\
\text { dual opposing linear } \\
\text { alternator }\end{array}$ & $\begin{array}{l}35.4 \text { bar } \\
\text { helium }\end{array}$ & 74 & $\Delta \mathrm{T}=620$ & $\begin{array}{l}450.9 \mathrm{~W}_{\mathrm{e}} \& \\
481 \mathrm{~W}_{\mathrm{e}, \max }\end{array}$ & $\begin{array}{c}15 . \%(\max ) \\
\& 12.7 \%\end{array}$ \\
\hline Sun et al. ${ }^{28}$ & \begin{tabular}{|c|} 
Loop-branched \& 2 \\
moving-magnet linear \\
alternators \\
\end{tabular} & $\begin{array}{l}30 \text { bar } \\
\text { helium }\end{array}$ & 64.5 & $\Delta \mathrm{T}=620$ & $\begin{array}{r}321.8 \mathrm{~W}_{\mathrm{e}} \& \\
345.3 \mathrm{~W}_{\mathrm{e}, \max }\end{array}$ & $\begin{array}{c}12.3 \%(\max ) \\
\& 9.3 \%\end{array}$ \\
\hline$\underset{29}{\text { Kang et al. }}$ & $\begin{array}{c}\text { Annular with a stub } \\
\& 2 \text { loudspeakers }\end{array}$ & $\begin{array}{l}18 \text { bar } \\
\text { helium }\end{array}$ & 171 & $\mathrm{n} / \mathrm{a}$ & $\begin{array}{l}183.6 \mathrm{~W}_{\mathrm{e}} \& \\
204 \mathrm{~W}_{\mathrm{e}, \max }\end{array}$ & $\begin{array}{c}3.4 \%(\max ) \\
\quad \& 3.4 \%\end{array}$ \\
\hline$\underset{30}{\text { Wang et al. }}$ & $\begin{array}{c}\text { Loop-branched \& } 2 \\
\text { moving-magnet linear } \\
\text { alternators } \\
\end{array}$ & $\begin{array}{c}24.8 \text { bar } \\
\text { helium }\end{array}$ & 65 & $\Delta \mathrm{T}=620$ & $473.6 \mathrm{We}_{\mathrm{e}}$ & $14.5 \%$ \\
\hline$\underset{31}{\text { Wang et al. }}$ & $\begin{array}{c}\text { Loop-branched \& } \\
\text { double-acting } \\
\text { alternators }\end{array}$ & $\begin{array}{c}31.6 \text { bar } \\
\text { helium }\end{array}$ & 65.5 & $\Delta \mathrm{T}=620$ & $750.4 \mathrm{~W}_{\mathrm{e}}$ & $16.3 \%$ \\
\hline Wu et al. ${ }^{32}$ & $\begin{array}{c}\text { Loop-branched \& two } \\
\text { moving-magnet linear } \\
\text { alternators }\end{array}$ & \begin{tabular}{|c|}
40 bar, \\
$4.5 \%$ \\
argon- \\
helium \\
\end{tabular} & 64 & $\Delta \mathrm{T}=635$ & $\begin{array}{c}970 \mathrm{~W}_{\mathrm{e}} \& \\
1043 \mathrm{~W}_{\mathrm{e}, \max }\end{array}$ & $\begin{array}{l}19.8 \%(\max ) \\
\& 17.7 \%\end{array}$ \\
\hline Wu et al. ${ }^{33}$ & $\begin{array}{c}\text { Three-stage annular } \\
\& \text { three linear } \\
\text { alternators }\end{array}$ & $\begin{array}{l}50 \text { bar } \\
\text { helium }\end{array}$ & 86 & $\Delta \mathrm{T}=620$ & $1570 \mathrm{~W}_{\mathrm{e}}$ & $16.8 \%$ \\
\hline Bi et al. ${ }^{34}$ & $\begin{array}{c}\text { Three-stage annular } \\
\& \text { three linear } \\
\text { alternators }\end{array}$ & $\begin{array}{l}60 \text { bar } \\
\text { helium }\end{array}$ & 70 & $\Delta \mathrm{T}=625$ & $\begin{array}{c}3.46 \mathrm{~kW}_{\mathrm{e}} \& \\
4.69 \mathrm{~kW}_{\mathrm{e}, \max }\end{array}$ & $\begin{array}{l}18.4 \%(\max ) \\
\& 15.6 \%\end{array}$ \\
\hline
\end{tabular}

$\mathrm{W}_{\mathrm{e}}$ : electric power; $\mathrm{W}_{\mathrm{e}, \max }$ : maximum electric power; $\%(\max )$ : maximum efficiency achieved. 
Resonator \& transducer data in Table 2 are indicative of the engine configuration. A resonant acoustic network is a wave guide in which the working gas is contained. The length and geometry of that waveguide and the physical properties of the working gas determine the frequency of the TA-SLiCE. Depending on the morphology of the resonant acoustic network, it will be found different types of Stirling engine configurations. The resonator is a passive component, i.e., it has no moving parts. There are many resonant acoustic network possible configurations, but the most common are the annular, loopedbranched and coaxial types, representative examples of which are shown in Figs. 2(a), 2(b) and 2(c), respectively. The (a) and (b) configurations in Fig. 2 employ a feedback loop that provides not only fluidic resistance but also inertance and compliance. The additional degree of freedom provided by this "transit", means that the pressure and acoustic wave displacement oscillations reaching the regenerator are locally out of phase by almost $90^{\circ}$ (meaning that pressure and volumetric velocity are practically in phase). The Stirling micro-cycle is therefore produced for those gas parcels (or particles) in the vicinity of the regenerator. As shown in Fig. 2(c), the thermal core region has an axial configuration, and the "transit" of the wavefront that feeds back to the core branch, is made along an internal connection tube.

a)
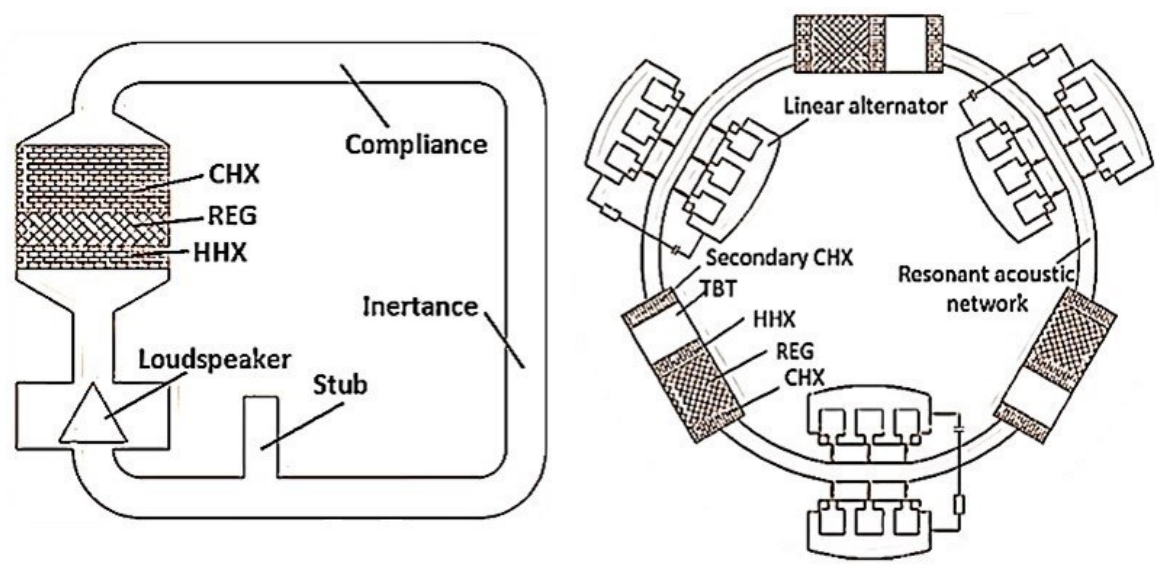

b)
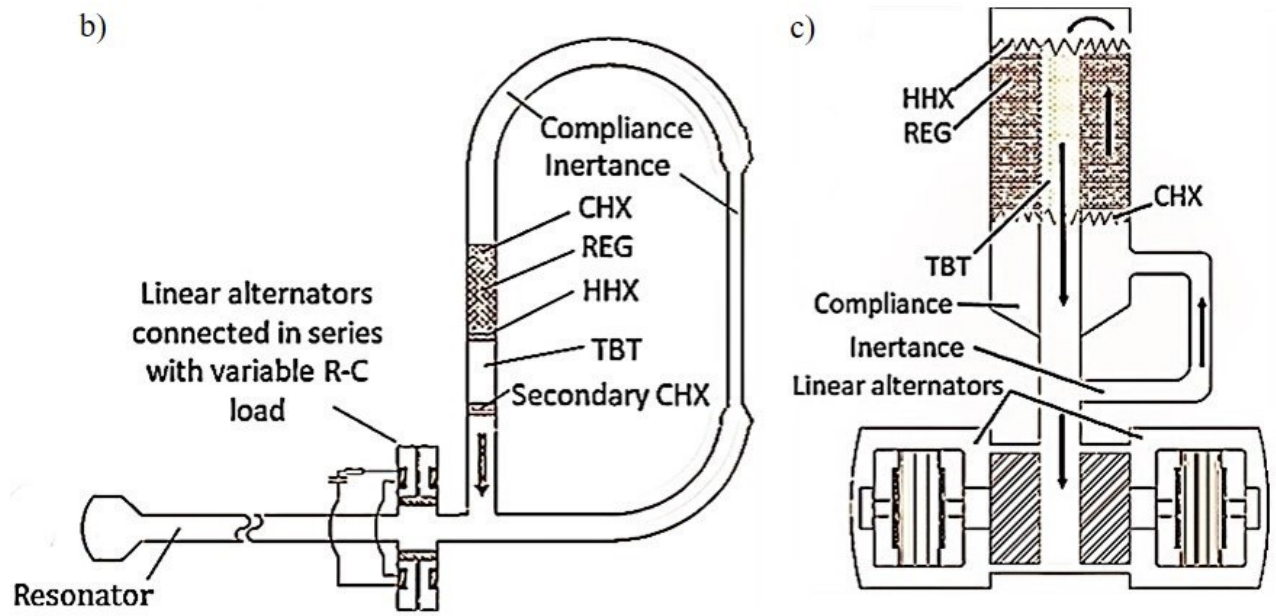

Fig. 2. Simplified diagram of different passive resonant acoustic network configurations: (a) annular type, (b) loop-branched type and (c) coaxial type. 
Mechanical resonators are basically mass and spring systems adapted to substantially replicate the dynamic conditions of the acoustic resonators at a position inside the acoustic network. The mass and spring alternative is selected to make the total system resonate at the same frequency as the gas column in the acoustic resonator. There are several types of mechanical resonators which can act as the power piston in a conventional Stirling engine. The simplest mechanical resonator is a piston that encloses a volume behind it that acts as a gas spring. However, all mechanical resonators are expensive, and, in addition, their use involves the introduction of a moving mass into the thermoacoustic engine. This fact eliminates a key advantage of TA-SLiCEs, namely, no moving solid parts. Besides, it is impossible to extract the electric energy of the engine without moving parts. In this respect, the extent to which the TA-SLiCE and the electroacoustic transducer are interrelated, is obvious. Clearly, by reducing the performance of the electro-acoustic transducer, the overall thermoelectric efficiency of the TA-SLiCE generator also decreases. Among the existing solutions for electroacoustic transduction, it is worth highlighting: Piezoelectric transducers ${ }^{35,36}$; Moving coil linear alternators (loudspeakers) ${ }^{18,29,37-40}$; Moving magnet linear alternators ${ }^{27,41,42}$; Magnetohydrodynamic generators (MHDs) ${ }^{43-46}$; and Bidirectional impulse turbines ${ }^{20,47,48}$.

According to the temperature data in Table 2, an analysis of electricity generation depending on the operating temperature supplied can be extracted. "Low and medium temperature" applications (i.e., up to $500{ }^{\circ} \mathrm{C}$ ) take advantage of thermal energy that would otherwise be dissipated in the environment. Most of the power generation for low or medium temperature heat sources research to date use other competing alternatives. Organic Rankine Cycle technology (ORC) is an important example. ORC is suitable for a wide range of applications, between $100 \mathrm{~kW}$ and $50 \mathrm{MW}$, low enthalpy geothermal sources exploitation, and waste heat recovery at relevant-scale applications: internal combustion engines, concentrated solar power systems, biomass plants and industrial processes being some examples. Regarding "low and medium temperature" applications, TA-SLiCE systems are currently highly inefficient. They currently can only be a viable alternative to other technologies that are not technically or economically viable. Low-cost thermoacoustic generation applications are in a promising development stage, due to the need for the provision of electricity to remote areas lacking accessibility to electricity networks. An example of this application is the SCORE project, where a feasibility study has already been already carried out. Similar devices could also be used to provide supplementary power in military bases, where energy isolation is a determining feature. "High temperature" applications $\left(500^{\circ} \mathrm{C}\right.$ or more) include devices used for electricity generation in space probes, such as HEPS (a NASA programme) or the Space TRIPS project (a European programme). In this high-temperature range, there are many prototypes under development that cannot reach the maximum theoretical efficiency, such as technologies based on the organic Rankine cycle (for several $\mathrm{kW}$ or MW ranges). However, in relation to the other technologies, a significant advantage of TA-SLiCEs is their mechanically simple design, with no moving parts.

\section{First steps in foundations}

This section briefly introduces the description of the passive resonant acoustic network of the TA-SLiCE in terms of lumped elements on the basis of the linear theory ${ }^{14}$. Among the important electroacoustic analogies, $p_{1}$ and $U_{1}$ correspond to $V_{1}$ and $I_{1}$, where $V_{1}$ is the voltage, and $I_{1}$ the current of the electric circuit.

The relationship between $p_{1}$ and $U_{1}$ is the acoustic impedance $\left(Z_{a}\right)$, and is analogous to the impedance $(Z)$ in an electric circuit ${ }^{49}$ : 


$$
Z_{a}=p_{1} / U_{1}=R_{a}+j\left(\omega L_{a}-1 / \omega C_{a}\right) \quad \leftrightarrow \quad Z=V_{1} / I_{1}
$$

$Z_{a}$ defines the resistive elements, inductive and capacitive waveguide to adapt the phase $\varnothing_{p u}$. At the acoustic networks, these elements are the acoustic resistance, the inertance and the compliance (in electric circuits: resistance, coil, and capacitor, respectively). An acoustic resistor dissipates energy by viscosity and by thermal relaxation when it is crossed by the fluid. It acts as a resistance would in an analogous electric circuit. It always consumes (or absorbs) useful power. The resistive load is totally real (it has no imaginary part) as shown in Eq. (1). However, inductive and reactive loads are elements that delay or advance respectively the volumetric velocity phase with respect to the pressure one. Compliance introduces positive phase changes, i.e., it acts as a capacitive load and introduces a $90^{\circ}$ phase change between $\left|p_{1}\right|$ and $\left|U_{1}\right|$ so that the volumetric velocity advances $90^{\circ}$ with respect to the pressure. Inertance introduces negative phase changes, i.e., it acts as an inductive load that introduces a $-90^{\circ}$ phase change between $|p 1|$ and $\left|U_{1}\right|$ so that the volumetric velocity is delayed by $90^{\circ}$ with respect to the pressure. Both inertance and compliance are totally imaginary as seen in Eq. (1) and yield or absorb power according to the instant considered. The impedance, defined in Eq. (1), has a real resistive part and an imaginary capacitive and inductive part.

Considering Eq. (1), the total power of the inductance $P_{Z}=V_{1} \times I_{1}$ is a phasor that can be broken down into active power on the real axis $\mathrm{P}_{\mathrm{A}}$, and into reactive power on the imaginary axis $\mathrm{P}_{\mathrm{R}}$.

\subsection{The reactive acoustic power methodology}

In this subsection is important to note that, when the amplified acoustic wave leaves the core branch, it has both a standing and a progressive contribution. This fact highlights the relevance of feedback for travelling wave adequacy at the input of the core branch. The methodology used in this paper proposes to take advantage of the information provided by the reactive acoustic power flow about the phase in which the wave arrives at the regenerator. The reactive acoustic power refers to the power that exists in a pure standing acoustic wave. The amount of reactive acoustic power delivered to the core branch varies depending on the dimensions of feedback branch compliance. When the feedback branch delivers less reactive acoustic power to the core branch, the wave arrives at the regenerator with a lower standing wave contribution, which means that the wave is closer to the desired progressive wave phase. Based on this analysis, the amount of reactive acoustic power distributed towards the core branch is a good indicator of the degree of travelling wave phase adequacy. Therefore, the reactive acoustic power methodology leads to a straight and comprehensive design process for the resonant acoustic network of a TA-SLiCE.

Applying the electroacoustic analogy, the real part of the phasor $\mathrm{P}_{\mathrm{Z}}$ is analogous to the active acoustic power flow. This variable averaged over an integral number of cycles, circulating in the $\mathrm{x}$ direction through a duct is given, according to the Rott approximation ${ }^{14}$, by the second order expression:

$$
\begin{gathered}
\dot{E}(x)=\frac{\omega}{2 \pi} \oint p U d t=\operatorname{Re}\left[p_{1}(x) e^{i \omega t}\right] \operatorname{Re}\left[U_{1}(x) e^{i \omega t}\right] d t=\frac{1}{2} \operatorname{Re}\left(\tilde{p}_{1} U_{1}\right)=\frac{1}{2} \operatorname{Re}\left(p_{1} \widetilde{U}_{1}\right) \\
=\frac{1}{2}\left|p_{1}\right|\left|U_{1}\right| \cos \emptyset_{p U}
\end{gathered}
$$


The imaginary part of the $\mathrm{P}_{\mathrm{Z}}$ phasor is analogous to the reactive acoustic power flow:

$$
\dot{Q}(x)=\frac{1}{2} \operatorname{Im}\left(\tilde{p}_{1} U_{1}\right)=\frac{1}{2}\left|p_{1}\right|\left|U_{1}\right| \operatorname{sen} \emptyset_{p U}
$$

where $\varnothing_{p U}$ is the angle between the pressure $p_{1}$ and the volumetric velocity $U_{1}$ of the acoustic wave. Using the electroacoustic analogy again, it follows that $\varphi=\varnothing_{p U}$.

The active acoustic power given by Eq. (2), represents the useful power since it is the only one that is transformed into work. The reactive power given by Eq. (3) is the one consumed by all the devices that have some type of coil or inductance. This type of energy only overloads any circuit, increasing the current (the volumetric velocity of the acoustic wave, by electroacoustic analogy) that circulates through it, without producing work. When an $\mathrm{AC}$ receiver absorbs reactive power, this power is positive and when it gives up, it has a negative value. As the reactive power of any coil is positive, it can be said that all coils absorb reactive energy. Following the same reasoning, the reactive power of any capacitor is negative and, therefore, all capacitors supply reactive power.

\subsection{Design strategy and analysis}

This section captures the work done in theoretically modelling and simulating the operation of a TA-SLiCE concept from a methodology which considers the active and reactive acoustic power flows. This additional information is essential for the energy analysis to establish the TA-SLiCE design.

The methodology for the TA-SLiCE design employed in this paper provides a comprehensive and easy-to-understand description of the phenomenon of progressive wave fitting due to the impedance of the acoustic network components. The compliance depends on its volume in a similar way as the capacitance of a given capacitor depends on its geometry. Each model variation has supposed an increment of compliance volume, which in the equivalent $\mathrm{AC}$ circuit implies a proportional condenser capacity increase. This is going to be illustrated by the following procedure: Based on a reference model, the dimensional parameters of the compliance are going to be modified twice to reduce the reactive power at the input of the active core. These modifications in the design, according to the established method, will lead to a more progressive acoustic wave.

The two compliance modifications give rise to three TA-SLiCE design models shown in Fig. 3, which difference between them is given by the dimensions of the feedback branch compliance.
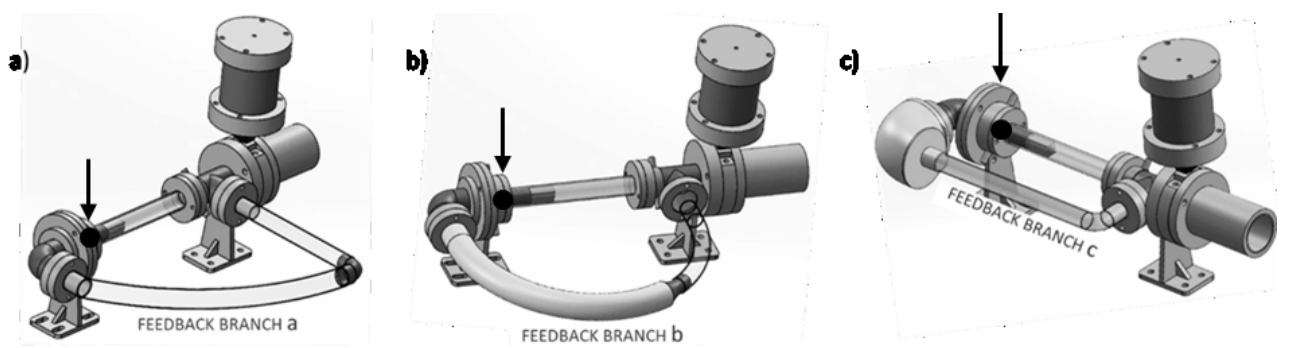

Fig. 3. Diagram of the reference model (a), first design variation model (b) and second design variation model (c) of the TA-SLiCE. The arrows point to the locations (black points) where the active and reactive acoustic power have been numerically calculated, at the regenerator entrance.

The reference model shown in Fig. 3(a), named "Fba", comprises a tube with $20 \mathrm{~mm}$ inside diameter used as compliance and another tube with $15 \mathrm{~mm}$ inside diameter is used 
for inertance. The first design variation model shown in Fig. 3(b), "Fbb", is modified by increasing the inside diameter of the compliance to $25 \mathrm{~mm}$. The second design variation model shown in Fig. 3(c), "Fbc" is modified by increasing again the inside diameter of the compliance to $66 \mathrm{~mm}$.

The following paragraphs highlight the most important aspects of the analysis of the power flows and the modification of the feedback branch TA-SLiCE for the reference model, where the active and reactive acoustic power have been numerically calculated in the black points located at the end of the arrows in Fig. 3. Once the acoustic power flows have been analysed in the reference model with "Fba" shown in Fig. 3(a), the system design can be modified. The modifications result in an active acoustic power similar to that obtained with the feedback branch "Fba" and a lower reactive acoustic power flow to the core branch at black point shown in Fig. 3(b). When comparing the data in Figs. 3(a) and 3 (b), the amplification of the active acoustic power through the core branch is slightly higher for feedback branch "Fbb" (813 to $1315 \mathrm{~mW}$ for "Fba" compared to "Fbb" from 811 to $1332 \mathrm{~mW}$ ). For the "Fba" feedback branch shown in Fig. 3(a), the reactive acoustic power delivered to the core branch is high and the wave arrives with less travelling wave condition, compared to the results obtained for the "Fbb" configuration shown in Fig. 3(b) (332 mWAr for "Fba" versus 283 mWAr for "Fbb"). This means that, without the information of the reactive acoustic power flow, it is possible to select the "Fba" when it is not the best option. Thus, the knowledge of the reactive acoustic power flow provides a straight TA-SLiCE design criterion.

With the "Fbc" feedback branch, a second modification is made that brings further improvements to the performance of the system. This configuration shown in Fig. 3(c) has a much shorter compliance and a larger section, compared to the other two previous configurations ("Fba" and "Fbb"). The comparative of the power flow distribution data from Figs. 3(b) and 3(c) shows that the active acoustic power is higher, and the reactive acoustic power is much lower (both calculated in the black point) for the feedback branch "Fbc" than for the feedback branch "Fbb" $(865 \mathrm{~mW} / 201 \mathrm{mWAr}$ versus $811 \mathrm{~mW} / 283$ mWAr). This means that the "Fbc" feedback branch provides a more powerful wave while reaching the core branch with a better travelling wave condition. When evaluating the results obtained for the reactive acoustic power calculated in the black point, it can be observed that the feedback branch "Fbc" distributes much less reactive acoustic power towards the core branch, indicating that the acoustic wave arrives at the regenerator with a more adjusted phase to the travelling wave condition compared to the other two feedback branch options. Furthermore, it follows that compliance should provide the minimum reactive acoustic power towards the core branch with the least active power loss. These requirements to improve the performance of the device using the reactive acoustic power flow method, suggest considering increasing the inside diameter and decreasing the length of the compliance, this leads to select a cavity type compliance with a section much larger than its length, instead of using duct type compliance, to achieve a similar volume.

\section{The praxis}

The theoretical analysis is certainly instructive, but as is usually the case when dealing with technological or engineering problems, it is the path to design that is most helpful in understanding the concepts. The maximum result is obtained with the construction of an experimental demonstrator. A challenge was proposed to a group of engineering students. The challenge was to understand, design, build and test a low-cost thermoacoustic engine with the use of the methodology, to put into practice what has been pointed out in the previous sections. 
As a starting point, they were provided with a DeltaEC model and low-cost materials such shown in Fig. 4, as Pyrex test tubes, copper tubes and joints, PVC tubes and joints and PLA supports for all the equipment, built with additive manufacturing with the $3 \mathrm{D}$ printers.

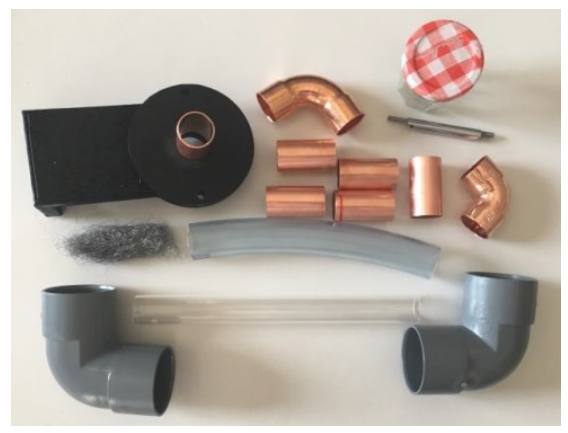

Fig. 4. Materials inventory for the construction of a thermoacoustic Stirling engine demonstrator.

After that, three multidisciplinary teams were created, balancing the knowledge of the students. It was considered that it was best to open the conference to students from all courses, from first to fourth. It is true that students in the first years may not be as well trained as those in the last years, but it is important to bear in mind that research promotion and training should be done from the bottom up, from the very beginning. A student with good grades who is recognized for his or her efforts from the first grade onwards, who is rewarded with an exclusive course and who has the opportunity to learn a new technology, together with students from higher grades and from the same or different grades, will experience a more complete integral formation than those in the last grades. Therefore, the challenge was opened to all courses and all engineering degrees (Automotive, Mechanical, Design and Industrial), offering the participation of the two best students of the promotion in each course and degree. The creation of transverse teams was a success. Students in more advanced courses played the role of natural leaders, while those in lower courses, with less experience, learned from them and supported the team in the things they could and knew how to do.

Each team was proposed to make a different model. The students had to study the DeltaEC model that was given to them, modify its parameters, following the reactive acoustic power methodology guidelines, and provide a better design than the previous team. The use of atmospheric air as a working gas allowed the possibility of using a low-cost Pyrex glass test tube as a thermal relaxation tube, which also contained the regenerator and hot heat exchanger. The properties of Pyrex glass make it not suitable for heating above the melting temperature of borosilicate glass. Therefore, the temperature difference in the regenerator can be set between 303 and $573 \mathrm{~K}$. Therefore, the machines were heated by the flame from an ethyl alcohol burner (96\% ethanol).

Qualitative tests were carried out to obtain the power of each demonstrator, and the methodology could indeed be validated, also qualitatively.

Each of the three teams measured experimentally the acoustic power delivered to the power extraction branch. Once the system reached a steady state of oscillation, the pressure in front of the piston and the resonator piston displacement signals were measured simultaneously using pressure and displacement sensors, respectively (Fig.5). The volume variation due to the movement of the piston could be inferred from the piston displacement measurements in the known moving piston section. Thus, the acoustic power delivered in front of the piston was obtained experimentally from the area enclosed in the $p V$ diagrams obtained from data. 


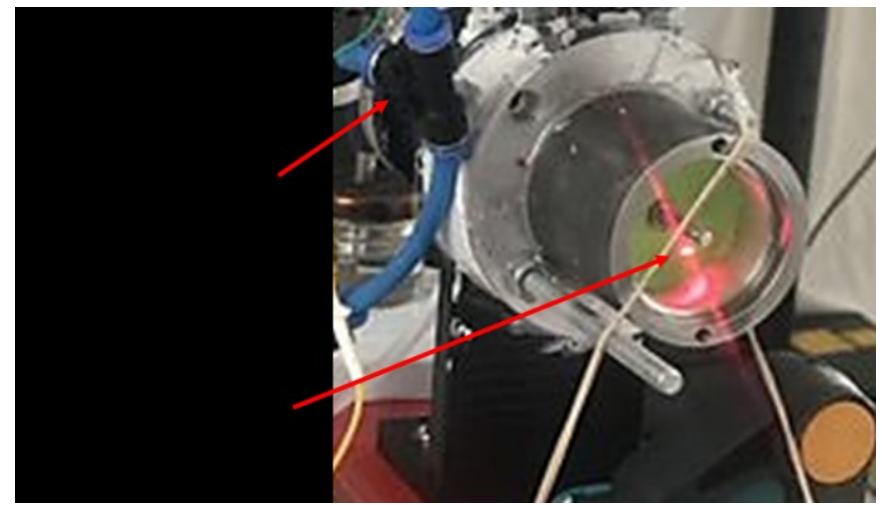

Fig. 5. Image of the experimental TA-SLiCE power extraction branch assembly.

The acoustic power output of the system activated a piston, the acoustic-to-mechanical energy transducer, located into the resonator of the power extraction branch. The most satisfactory result was obtained for the device shown in Fig. 6 with a power output of about $8 \mathrm{~W}$.

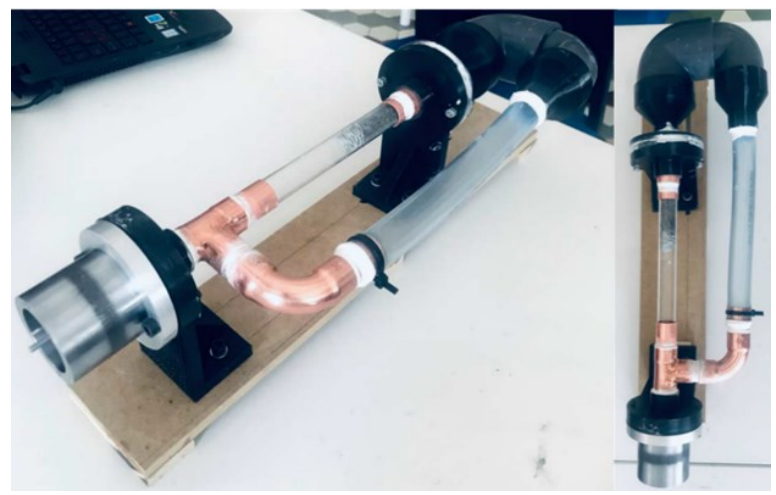

Fig. 6. Demonstrator with the better power output.

All students showed great motivation for the challenge of learning. They were surprised by the research being done at the Nebrija University on the subject of thermoacoustics and came to understand a little better what is needed for research. In fact, two of these students were incorporated into the research group as students who did their professional practice in research work.

\section{Conclusions and future work}

In this paper it has been demonstrated that thermoacoustics is a strongly multidisciplinary technology, where interactions between thermodynamic, physical and acoustic concepts are interwoven, which are affected by the mechanical construction, the fluid dynamics of the system, the engineering of materials, heat exchange processes, wave generation and acoustic, mechanic and electric energy generation, among others.

It is therefore the application of knowledge from different branches of science that collaborate with each other to develop thermoacoustic technology. A priori, it can be thought that these concepts are complex for general audience since, the application and integration of all the "Physics" to create a functional machine is far from simple. Similarly, 
in research, it is not easy to get started in a field that is as exciting as it is initially challenging because of the need to master so many different fields of knowledge.

There are limited research groups worldwide engaged in the development of thermoacoustic technology. In the same way, being a young technology, it is not easy to find companies that commercialize thermoacoustic products. One of the main challenges of thermoacoustic technology is to know if it will be able to demonstrate its differential value and effectiveness against more mature technologies. For this, it is necessary to investigate in thermoacoustics, for which it is necessary that there are universities that have research groups in this technology and, later, companies can be created that commercialize competitive thermoacoustic products.

There are therefore many challenges and great uncertainties until thermoacoustics can compete in the future with technologies already established in the market. However, it is also true that this technology has many advantages over more established ones, but it has not yet been able to develop completely.

The method of reactive acoustic power distribution significantly provides comprehension about the traveling-wave phasing, critical for efficient regenerator operation, and how various components of the feedback branch affect these properties. Numerical modelling of the demonstrator previously described is used to evaluate by comparing three feedback branch options. The effectiveness to distribute the reactive acoustic power, generated by the compliance, in order to favour adjusting of traveling-wave phasing is assessed for each of the three feedback branches under study. Besides, the presented method uses simply algebraic power sums, and it has not the need to handle complex phasor notation. This is analogous to the analysis carried out in an electric circuit, emphasizing the importance of the reactive power, in addition to the active power through each segment of the system.

Therefore, it can be concluded that the objective pursued of being able to interest students in research in general, and in thermoacoustic technology in particular; and the recruitment of future researchers was successful.

As a general conclusion, this paper aims to present a book which, as has been demonstrated in this work, is an excellent tool for science and engineering teachers. The book "INTRODUCTION TO THERMOACOUSTIC STIRLING ENGINES: FIRST STEPS IN FOUNDATIONS AND PRAXIS" can help to transmit and consolidate knowledge in thermodynamics and wave mechanics, complementing the teachings with accessible practices for everyone.

The authors thank the Global Nebrija-Santander Chair of Energy Recovery in Surface Transport for their financial support. This work was also supported by the Agencia Estatal de Investigación [grant RETOS 2018-RTI2018-095923-B-C22].

\section{References}

1. Kölsch, B. \& Radulovic, J. Utilisation of diesel engine waste heat by Organic Rankine Cycle. Appl. Therm. Eng. 78, 437-448 (2015).

2. Zhao, R. et al. Parametric study of a turbocompound diesel engine based on an analytical model. Energy 115, 435-445 (2016).

3. Pasini, G. et al. Evaluation of an electric turbo compound system for SI engines : A numerical approach. Appl. Energy 162, 527-540 (2016).

4. Kim, T. Y., Kwak, J. \& Kim, B. Energy harvesting performance of hexagonal shaped thermoelectric generator for passenger vehicle applications: An experimental approach. Energy Convers. Manag. 160, 14-21 (2018).

5. Sahoo, D., Kotrba, A., Steiner, T. \& Swift, G. Waste Heat Recovery for Light-Duty 
Truck Application Using ThermoAcoustic Converter Technology. SAE Int. J. Engines 10, 196-202 (2017).

6. Uppuluri, S., Khalane, H., Naiknaware, A., Sahoo, D. \& Kotrba, A. Exhaust Technologies in Support of LD and HD Reductions of GHGs and Criteria Pollutants. in Vehicle Thermal Management Systems Conference 127-140 (2017).

7. Mansour, C., Bou Nader, W., Dumand, C. \& Nemer, M. Waste heat recovery from engine coolant on mild hybrid vehicle using organic Rankine cycle. Proc. Inst. Mech. Eng. Part D J. Automob. Eng. 233, 2502-2517 (2019).

8. Reine, A. \& Bou Nader, W. Fuel consumption potential of different external combustion gas-turbine thermodynamic configurations for extended range electric vehicles. Energy 175, 900-913 (2019).

9. Bou Nader, W. Thermoelectric generator optimization for hybrid electric vehicles. Appl. Therm. Eng. 167, 114761 (2020).

10. Bou Nader, W., Chamoun, J. \& Dumand, C. Thermoacoustic engine as waste heat recovery system on extended range hybrid electric vehicles. Energy Convers. Manag. 215, 112912 (2020).

11. Backhaus, S. \& Swift, G. W. A thermoacoustic-Stirling heat engine: Detailed study. J. Acoust. Soc. Am. 107, 3148-3166 (2000).

12. $\mathrm{Yu}, \mathrm{Z}$. \& Jaworski, A. J. Impact of acoustic impedance and flow resistance on the power output capacity of the regenerators in travelling-wave thermoacoustic engines. Energy Convers. Manag. 51, 350-359 (2010).

13. Timmer, M. A. G., de Blok, K. \& van der Meer, T. H. Review on the conversion of thermoacoustic power into electricity. J. Acoust. Soc. Am. 143, 841-857. DOI: 10.1121/1.5023395 (2018).

14. Swift, G. W. Thermoacoustics: A Unifying Perspective for Some Engines and Refrigerators. (ASA Press/Springer. ISBN:978-3-319-66932-8, 2017).

15. Hu, Z. J., Li, Z. Y., Li, Q. \& Li, Q. Evaluation of thermal efficiency and energy conversion of thermoacoustic Stirling engines. Energy Convers. Manag. 51, 802812 (2010).

16. Iniesta, C., Olazagoitia, J. L., Vinolas, J. \& Gros, J. New method to analyse and optimise thermoacoustic power generators for the recovery of residual energy. Alexandria Eng. J. 59, 3907-3917 (2020).

17. Iniesta, C., Olazagoitia, J. L., Gros, J., Vinolas, J. \& Aranceta, J. Introduction to thermoacoustic Stirling engines: First steps in foundations and praxis. (Thomson Reuters, 2020).

18. Yu, Z., Jaworski, A. J. \& Backhaus, S. Design of a low-cost thermoacoustic electric generator and its experimental verification. in Procceding ASME 10th Biennial Conference on Engineering Systems Design and Analysis. 12-14July 191-199 (2010).

19. Chen, B. M., Abakr, Y. A., Riley, P. H. \& Hann, D. B. Development of thermoacoustic engine operating by waste heat from cooking stove. AIP Conf. Proc. 1440, 532-540 (2012).

20. De Blok, K. On the design of near atmospheric air operated thermoacoustic engines.

21. Backhaus, S., Tward, E. \& Petach, M. Traveling-wave thermoacoustic electric generator. Appl. Phys. Lett. 85, 1085-1087 (2004).

22. Telesz, M. P. Design and testing of a thermoacoustic power converter. (Master Thesis, Georgia Institute of Technology, USA, 2006).

23. Luo, E., Wu, Z., Dai, W., Li, S. \& Zhou, Y. A $100 \mathrm{~W}$-class traveling-wave thermoacoustic electricity generator. Chinese Sci. Bull. 53, 1453-1456 (2008).

24. Kloprogge, T. Turbine Design for Thermoacoustic Generator. (Graduation project, 
Inholland University of Applied Sciences, The Netherlands, 2012).

25. Wilcox, D. Experimental investigation of a thermoacoustic-Stirling engine electric generator with Gedeon streaming supression. (Master Thesis. The Pennsylvania State University, USA, 2011).

26. Wang, Y., Li, Z. \& Li, Q. A novel method for improving the performance of thermoacoustic electric generator without resonator. Energy Convers. Manag. 110, 135-141 (2016).

27. Wu, Z. H., Man, M., Luo, E. C., Dai, W. \& Zhou, Y. Experimental investigation of a $500 \mathrm{~W}$ traveling-wave thermoacoustic electricity generator. Chin Sci Bull vol. 56 1975-1977 (2011).

28. Sun, D. M. et al. A traveling-wave thermoacoustic electric generator with a variable electric R-C load. Appl. Energy 106, 377-382 (2013).

29. Kang, H., Cheng, P., Yu, Z. \& Zheng, H. A two-stage traveling-wave thermoacoustic electric generator with loudspeakers as alternators. Appl. Energy 137, 9-17 (2015).

30. Wang, K. et al. Operating characteristics and performance improvements of a $500 \mathrm{~W}$ traveling-wave thermoacoustic electric generator. Appl. Energy 160, 853862 (2015).

31. Wang, K. et al. An acoustically matched traveling-wave thermoacoustic generator achieving $750 \mathrm{~W}$ electric power. Energy 103, 313-321 (2016).

32. Wu, Z., Zhang, L., Dai, W. \& Luo, E. Investigation on a $1 \mathrm{~kW}$ traveling-wave thermoacoustic electrical generator. Appl. Energy 124, 140-147 (2014).

33. Wu, Z., Yu, G., Zhang, L., Dai, W. \& Luo, E. Development of a 3kW doubleacting thermoacoustic Stirling electric generator. Appl. Energy 136, 866-872 (2014).

34. Bi, T. et al. Development of a $5 \mathrm{~kW}$ traveling-wave thermoacoustic electric generator. Appl. Energy 1-7 (2015) doi:10.1016/j.apenergy.2015.12.034.

35. Keolian, R. \& Bastyr, K. Thermoacoustic piezoelectric gerenator. (2006).

36. Keolian, R. \& Backhaus, S. Energy conversion through thermoacoustics and piezoelectricity. J. Acoust. Soc. Am. 130, 2504 (2011).

37. Yu, Z., Jaworski, A. J. \& Backhaus, S. A low-cost electricity generator for rural areas using a travelling-wave looped-tube thermoacoustic engine. Proc. Inst. Mech. Eng. Part A J. Power Energy 224, 787-795 (2010).

38. Yu, Z., Saechan, P. \& Jaworski, A. J. A method of characterising performance of audio loudspeakers for linear alternator applications in low-cost thermoacoustic electricity generators. Appl. Acoust. 72, 260-267 (2011).

39. Jaworski, a. J. \& Mao, X. Development of thermoacoustic devices for power generation and refrigeration. Proc. Inst. Mech. Eng. Part A J. Power Energy 227, 762-782 (2013).

40. Rossi, A., Immovilli, F., Bianchini, C., Bellini, A. \& Serra, G. Design of linear alternators for thermoacoustic machines. in 2009 IEEE Energy Conversion Congress and Exposition 2436-2440 (IEEE). doi:10.1109/ECCE.2009.5316142.

41. Petach, M., Tward, E. \& Backhaus, S. Design and Testing of A Thermal to Electric Power Converter Based On Thermoacoustic Technology. in 2nd International Energy Conversion Engineering Conference (American Institute of Aeronautics and Astronauti).

42. Gonen, E. \& Grossman, G. Effect of variable mechanical resistance on electrodynamic alternator efficiency. Energy Convers. Manag. 88, 894-906 (2014).

43. Migliori, A. \& Swift, G. W. Liquid-sodium thermoacoustic engine. Appl. Phys. Lett. 53, 355-357 (1988).

44. Castrejón-Pita, A. A. \& Huelsz, G. Heat-to-electricity thermoacoustic- 
magnetohydrodynamic conversion. Appl. Phys. Lett. 90, 174110 (2007).

45. Mirhoseini, S. M. H. \& Alemany, A. Analytical study of thermoacoustic MHD generator. Magnetohydrodynamics 51, 519-530 (2015).

46. Roux, J.-P., Alemany, A. \& Montisci, A. Thermoacoustic magnetohydrodynamic electric generator. 1-14 (2015).

47. Dovgjallo, A. A. I., Tsapkova, A. B. \& Shimanov, A. A. Bi-Directional Impulse Turbine for Thermo-Acoustic Generator. in 18th International Conference on Energy Efficiency and Renewable Energy Technologies vol. 3.

48. Boessneck, E. T. \& Salem, T. E. Performance Characterization of Bi-Directional Turbines for Use in Thermoacoustic Generator Applications. in Proceedings of ASME 2016 10th International Conference on Energy Sustainability (ASME, 2016).

49. Jin, T. Preliminary Study on Circuit Simulation of Thermo Acoustic Engines. in AIP Conference Proceedings vol. 823 1103-1108 (AIP, 2006). 